\title{
BIOMOLECULAR CONCEPTS
}

EXECUTIVE EDITOR-IN-CHIEF

Pierre Jolles, Paris, France

EDITOR-IN-CHIEF

Isabelle Mansuy, Zurich, Switzerland
EDITORIAL BOARD

Jesús Avila, Madrid, Spain

Mathieu Bollen, Leuven, Belgium

Valentina Bonetto, Milan, Italy

Enrico Di Cera, St Louis, USA

Hans Jörnvall, Stockholm, Sweden

Eric Jorgensen, Salt Lake City, USA

Eric Lagasse, Pittsburgh, USA

Robert I. Norman, Leicester, United Kingdom

Lorenzo A. Pinna, Padua, Italy

K. Vijay Raghavan, Bangalore, India

Pál Venetianer, Szeged, Hungary

Walter Wahli, Lausanne, Switzerland 
ABSTRACTED/INDEXED IN Chemical Abstracts and the CAS databases; EBSCO - Academic Search; Scopus.

The publisher, together with the authors and editors, has taken great pains to ensure that all information presented in this work (programs, applications, amounts, dosages, etc.) reflects the standard of knowledge at the time of publication. Despite careful manuscript preparation and proof correction, errors can nevertheless occur. Authors, editors and publisher disclaim all responsibility for any errors or omissions or liability for the results obtained from use of the information, or parts thereof, contained in this work.

The citation of registered names, trade names, trademarks, etc. in this work does not imply, even in the absence of a specific statement, that such names are exempt from laws and regulations protecting trademarks etc. and therefore free for general use.

\section{ISSN 1868-5021·e-ISSN 1868-503X· CODEN BCIOB8}

All information regarding notes for contributors, subscriptions, Open access, back volumes and orders is available online at http://www.degruyter.com/biomolcon.

RESPONSIBLE EDITORS Professor Dr. Pierre Jolles, Museum National d'Histoire Naturelle, MCAM, CP54, 63, rue Buffon, F-75005 Paris, France, Email: Pierre.jolles@wanadoo.fr; jolles.pierre@bluewin.ch

Professor Dr. Isabelle Mansuy, Brain Research Institute, University of Zürich, Swiss Federal Institute of Technology Zürich, Winterthurerstrasse 190, CH-8057 Zürich, Switzerland, Email: mansuy@hifo.uzh.ch

JOURNAL MANAGER Dr. Torsten Krüger, De Gruyter, Genthiner Straße 13, 10785 Berlin, Germany, Tel.: +49 (0)30 26005 - 176 , Fax: +49 (0)30 26005 - 298, Email: biomol.concepts.editorial@ degruyter.com

RESPONSIBLE FOR ADVERTISEMENTS Panagiota Herbrand, De Gruyter, Rosenheimer Straße 143, 81671 München, Germany, Tel.: +49 (0)89 76902 - 394, Fax: +49 (0)89 76902 - 350, Email: panagiota.herbrand@ degruyter.com

(C) 2014 Walter de Gruyter GmbH, Berlin/Boston

TYPESETTING Compuscript Ltd., Shannon, Ireland

PRINTING Franz X. Stückle Druck und Verlag e.K., Ettenheim Printed in Germany

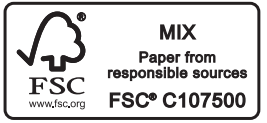




\section{Contents}

\section{Reviews}

Reuben M. Buckley and David L. Adelson

Mammalian genome evolution as a result of epigenetic

regulation of transposable elements -183

Xin Yao Qiu and Xiao Qian Chen

Neuroglobin - recent developments - 195

Gianluigi Franci, Alfonso Ciotta and Lucia Altucci

The Jumonji family: past, present and future of histone

demethylases in cancer 209

Takenori Onaga

Tachykinin: recent developments and novel roles in

health and disease -225
Lasse Dahl Jensen, Charlotte Gyllenhaal and Keith Block Circadian angiogenesis -245

\section{Short Conceptual Overview}

Michael Landreh, Linus J. Östberg, Tom M. Pettersson and Hans Jörnvall

Transthyretin microheterogeneity and molecular interactions: implications for amyloid formation -257 